\title{
Consumption-based accounting of steel alloying elements and greenhouse gas emissions associated with the metal use: the case of Japan
}

\author{
Hajime Ohno ${ }^{1 *}$, Kazuyo Matsubae ${ }^{2}$, Kenichi Nakajima $^{3}$, Keisuke Nansai $^{3}$, Yasuhiro Fukushima ${ }^{1}$ \\ and Tetsuya Nagasaka ${ }^{1}$
}

\section{*Correspondence:}

ohno@sis.che.tohoku.ac.jp

${ }^{1}$ Graduate School

of Engineering, Tohoku

University, Miyagi 980-8579,

Japan

Full list of author information

is available at the end of the article

\begin{abstract}
Metal extraction and smelting cause considerable impacts on the environment. Consumption-based impact accounting highlights the responsibility of metal-consuming industries for the impacts and may drive a system-wide improvement in the structure of related supply chains. To drive the improvements, policies at national level coordinated for respective product types across the nations is needed. However, nationwide responsibility for specific use of metals is difficult to identify because metals are manufactured into composite products (e.g., vehicles) in a country that is in many cases, different from the country where mining is practiced. The final product environmental footprints would not reveal the location where the various impacts are caused. This study presents a method to support the policy coordination by identifying the magnitude of the responsibility of metal-consuming countries for environmental impacts occurred in mining countries so that the countries sharing large responsibilities can find partner countries to jointly work on reduction in environmental impacts effectively. An input-output-based material flow analysis model is used to track the flows of metals included in products made in Japan throughout the international supply chain. In 2005, Japanese industries collected steel alloying elements (manganese, chromium, nickel, molybdenum) embodying $3200 \mathrm{kt}-\mathrm{CO}_{2}$ eq and distributed them as both intermediate and final products. For steel mill products, Asian countries were the main destination, while alloying elements contained in other products were relatively evenly exported to Asia, Europe, and North America. By consuming products made in Japan, South Korea, China, the USA, and Taiwan shared approximately $10 \%$ each in terms of share of responsibility for greenhouse gas emission embodied in alloying element collected by Japan. Japan shared $40 \%$ of the responsibility with domestic consumption of own products. These findings suggest that Japan, a collector and distributor of steel alloying elements, must work on its own resource use reduction policies coordinating with these countries to globally develop sustainable resource use system.
\end{abstract}

Keywords: Material flow analysis, Input-output analysis, International trade, Steel alloying element, Greenhouse gas emissions, Consumption base 


\section{Background}

Metals are indispensable in our society. To obtain sufficient metals for economic development, huge amounts of ores and industrial minerals are extracted globally (United Nations Environment Programme (UNEP) 2011); on the other hand, metal mining and smelting cause negative environmental impacts (Nuss and Eckelman 2014). Because the impacts of these processes directly affect the environment of mining and material processing countries, metal-consuming countries have indirect responsibilities for the impacts occurred in metal-producing countries according to own consumptions (Peters 2008; Peters and Hertwich 2008).

Once metals have been mined, smelted, and refined, they are consumed in the mined country and/or exported. Countries that import metals use them to produce various value-added products, consume the products themselves, and/or export them. However, this supply chain is unevenly distributed among countries. Mined metals tend to be collected by industrialized countries and then redistributed in the form of finished products through the international supply chain (Wiebe et al. 2012; Nansai et al. 2014; Wiedmann et al. 2015).

As the UNEP International Resource Panel points out, decoupling resource use and negative environmental impacts from economic growth is important for the development of a sustainable society (UNEP 2011). Improving resource efficiency and/or productivity is one of the key concepts for decoupling, although countries have been tackling such improvements in their own ways, which may not be the best approach to reaching the overarching objective. Consumption-based impact accounting, which considers the responsibility for environmental impacts in upstream supply chains, is different in that it places the responsibility on those countries that benefit from the products (Peters 2008; Peters and Hertwich 2008; Shigetomi et al. 2015, 2016). For example, if demand in country A for the products of country B induces huge resource use in country B, country A would be obliged to contribute to the activities in country B for improving resource efficiency and/or productivity. In this regard, the need for decoupling should be tackled through international cooperation.

In this paper, we demonstrate how a country can identify the magnitude of the responsibility sharing with other countries and find out the target countries to jointly work on impact reduction. Moreover, the flow of metals accompanying with international trade is revealed and the environmental impacts on the countries in the supply chain are organized to discuss the nature of the international coordination. A case study is then demonstrated by using the case of Japan and its use of alloying metal in the steel industry.

As an industrialized country, Japan contributes highly to the international flow of metals; Japan, who has the second largest steel production and third largest automobile production in the world (International Organization of Motor Vehicle Manufactures (OICA) 2015; World Steel Association 2015) without having any resource deposits, has considerable responsibilities for metal mining countries in order to drive its large metal fabricating industries. At the same time, Japan exports more than $40 \%$ of the produced steel mill products (World Steel Association 2015) and around 50\% of the produced automobiles (Japan Automobile Manufacture Association (JAMA) 2015) every year. Hence, Japan is passing on the responsibility for metal use to consuming countries as well as exporting metal-containing products (Kondo et al. 1998; Peters 2008). In terms 
of alloying elements, Japan consumes about $10 \%$ of the world's steel alloying elements (Japan Oil Gas and Metals National Corporation (JOGMEC) 2008). Among steel alloying elements, we focus on manganese, chromium, nickel, and molybdenum whose consumption in steel industries is relatively great compared with those in other industries in Japan (JOGMEC 2007). Steel alloying elements add various properties to steel such as corrosion resistance, heat resistance, and toughness (Nakajima et al. 2013). Steel mill products containing alloying elements (so-called alloy steel) are utilized widely in industries requiring high-performance materials, such as the automobile and machinery industries.

The content of alloying elements in steel mill and other fabricated products is estimated by using the waste input-output material flow analysis (WIO-MFA) model (Nakamura et al. 2007; Nakajima et al. 2013; Ohno et al. 2014). By using the WIO-MFA model to identify the content of alloying elements, metal compositions in highly fabricated products are derived based on IO analysis, whereas the representative compositions must be carefully chosen in process-based bottom-up MFAs.

Nansai et al. $(2009,2012)$ evaluated the carbon footprints of 230 countries and regions induced by Japanese economic activities by using the global link IO model. Their approach of connecting Japanese IO tables with international trade information is well suited to the use of WIO-MFA. Nakajima et al. (2011a) and Nansai et al. (2014) calculated the flows of metals accompanying with Japan's international trade by combining the WIO-MFA and global link IO models. Furthermore, Nakajima et al. (2014) addressed the global supply chain of nickel and examined its influence on the environment of mining sites.

Following this previous research, we examine the following three factors:

1. The flow of steel alloying elements collected by Japan by distinguishing domestic use from exports;

2. The international flow of steel alloying elements accompanying with the exports of Japanese products; and

3. The responsibility for environmental impacts in mining and material processing countries, using greenhouse gas (GHG) emissions as a proxy for the environmental impact in mining and material processing countries.

The study and inventory data of lifecycle assessment for metal production (Ecoinvent 2010; Eckelman 2010; Nuss and Eckelman 2014) are referred for accounting GHG emission in mining and material processing countries.

As shown in Fig. 1, we untangle the links between mining countries and both Japan and countries who import products made in Japan according to consumption-based thinking in order to clarify the attribution of the responsibility for environmental impacts in mining and material processing countries. We then discuss who should be involved in the activities of a country to improve resource efficiency. For the accounting method of the responsibility, Lenzen et al. (2007) proposed "shared responsibility" between producer and consumer. In this accounting, the shortcomings of both full producer and full consumer responsibility accountings such as double counting and lack of full life cycle description can be filled up by allocating responsibilities among the supply 


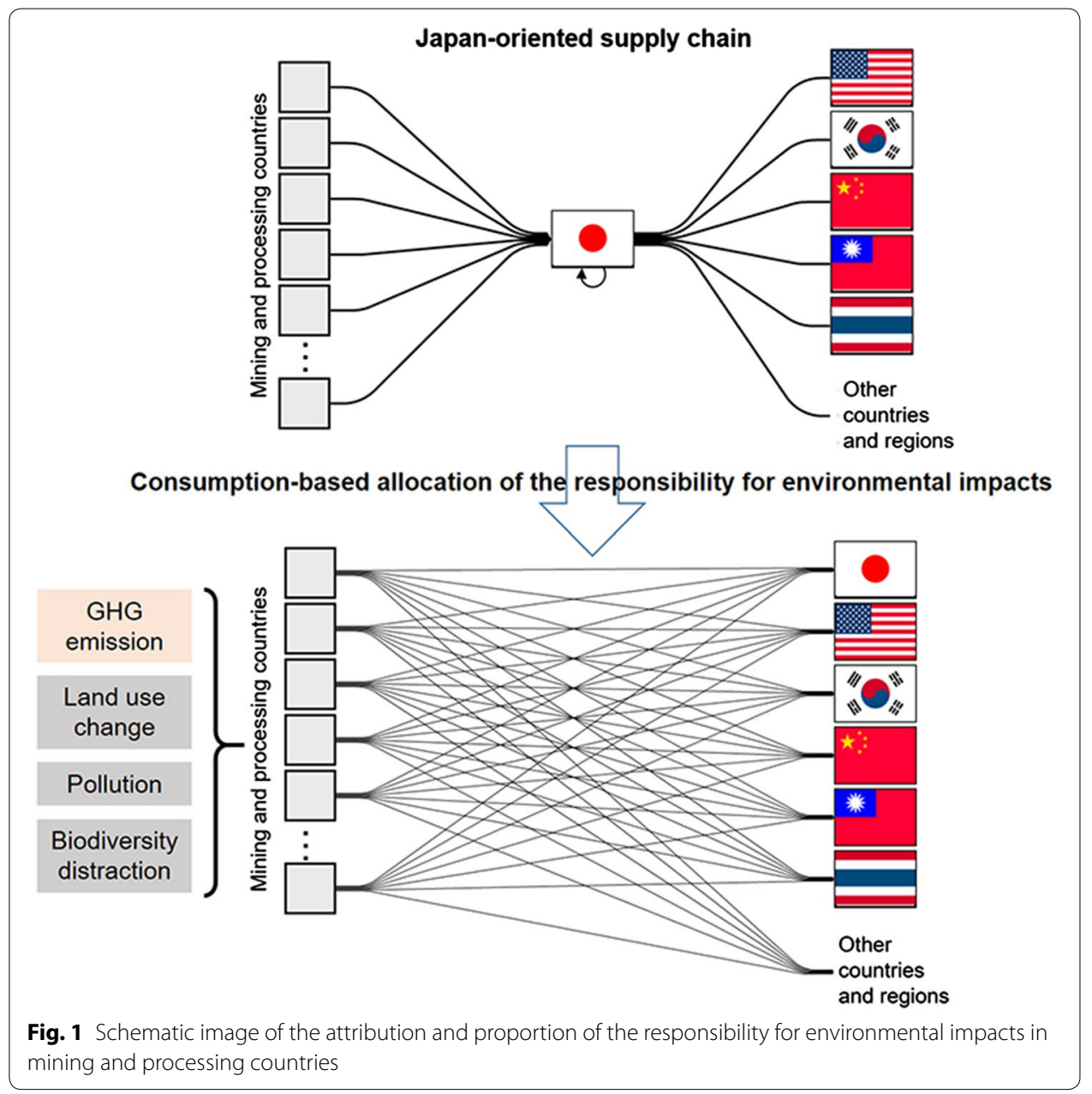

chain. Although the present study also argues about producers (i.e., mining and metal processing countries) and consumers (i.e., metal-consuming countries) in the supply chain as the same as Lenzen et al. (2007), we only take consumer responsibility for the impact directly occurred in producer countries into account. In other words, we distinguish environmental impacts on metal mining and producing countries from total environmental impacts including on metal processing countries and allocate the responsibility for the impacts on mining and producing countries to metal-consuming countries according to the share of metal-including products made in Japan. It is because impacts of mining and primary metal production tend to directly and quickly affect the surrounding environment and biodiversity rather than climate change derived by GHG emission (Nakajima et al. 2014). Ironically, however, we quantify the impact in terms of GHG emission as a proxy for the environmental impact in metal mining and producing countries instead of on the typical direct impacts such as land use changes and/or biodiversity threats which we indeed want to evaluate due to the lack of inventory data on them. The difficulty is that metals are mined in different methods such as open pit and pit mining, different forms such as oxide ore or sulfide ore, and smelted with different processes such as hydro- and/or pyro-metallurgy. This variety makes it difficult to create 
homogeneous inventory data about direct impacts for each metal. For the same reason, producers of metal resources providing metals for Japan are not particularly focused on.

\section{Methodology and data}

\subsection{WIO-MFA}

WIO-MFA provides the composition of materials in commodities by counting the direct and indirect flows of materials in an economy based on IO analysis. The composition of materials in commodities $\mathbf{C}_{\mathrm{MP}}$ is derived as follows:

$$
\mathbf{C}_{\mathrm{MP}}=\tilde{\mathbf{A}}_{\mathrm{MP}}\left(\mathbf{I}-\tilde{\mathbf{A}}_{\mathrm{PP}}\right)^{-1}
$$

Here, $\tilde{\mathbf{A}}$ represents the "filtered" input coefficient matrix and the subscripts $\mathrm{M}$ and $\mathrm{P}$, respectively, denote materials and products, indicating the category of inputs and outputs. "Filtered" means that the inputs do not form mass of a product (i.e., services, electricity, and process losses of materials) that are removed from the general input coefficient matrix by multiplying filter matrices (Nakamura et al. 2007). $\tilde{\mathbf{A}}_{\mathrm{MP}}$ stands for the matrix of the input coefficients of materials to the production of products, and $\tilde{\mathbf{A}}_{P P}$ is for the input of products to the production of products.

The unit of elements in $\tilde{\mathbf{A}}_{\mathrm{MP}}$ is the physical unit per monetary unit (e.g., ton/million

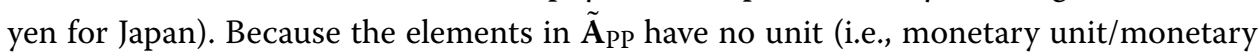
unit), the unit of elements in $\mathbf{C}_{\mathrm{MP}}$ becomes the physical unit per monetary unit as well as $\tilde{\mathbf{A}}_{M P}$. This means that the $(i, j)$-element of $\mathbf{C}_{\mathrm{MP}}$ represents the mass of material $i$ directly and indirectly introduced in one monetary unit of production of product $j$. In the case of Japanese IO, for instance, when material $i$ and product $j$ are pig iron and passenger cars, respectively, the meaning of the $(i, j)$-element of $\mathbf{C}_{\mathrm{MP}}$ is the mass of pig iron contained in one million yen of passenger cars. For steel mill products, their inputs and productions are expressed in physical units instead of monetary units for other products. Thus, the elements in $\mathbf{C}_{\mathrm{MP}}$ represent the mass of materials directly and indirectly contained in one physical unit of products. By introducing a vector $\mathbf{q}_{e}$ representing contents of alloying element $e$ in each material, $\mathbf{C}_{\mathrm{MP}}$ can be converted to $\mathbf{C}_{\mathrm{MP}}^{e}$ representing contents of alloying element $e$ in products.

$$
\mathbf{C}_{\mathrm{MP}}^{e}=\mathbf{q}_{e}^{\mathrm{T}} \mathbf{C}_{\mathrm{MP}}
$$

Here, $\mathbf{q}_{e}^{\mathrm{T}}$ represents transpose of $\mathbf{q}_{e}$. For further details on the model, see previous studies (Nakamura and Nakajima 2005; Nakamura et al. 2007).

\subsection{MFA of alloying elements in domestic final demand and export}

Let $\mathbf{T}$ be the matrix whose $(i, j)$-element represents the amount of goods $i$ exported from Japan to country or region $j$ and $\mathbf{D}_{e}^{\text {Exp }}$ be the matrix of the mass of accompanying alloying element $e$ with the export in goods $i$ with country or region $j$. By applying $\mathrm{C}_{\mathrm{MP}}^{e}$ obtained which represents the vector of contents of alloying element $e$ in products, $\mathbf{D}_{e}^{\text {Exp }}=\left(d_{\text {eij }}^{\text {Exp }}\right)$ can be estimated as follows:

$$
\mathbf{D}_{e}^{\text {Exp }}=\operatorname{diag}\left(\mathbf{C}_{\mathrm{MP}}^{e}\right) \mathbf{T}
$$


Similarly, the mass of alloying elements contained in final products domestically consumed in Japan is obtained as follows:

$$
\mathbf{D}_{e}^{\mathrm{JP}}=\operatorname{diag}\left(\mathbf{C}_{\mathrm{MP}}^{e}\right) \mathbf{f}^{\mathrm{JP}}
$$

Here, $\mathbf{D}_{e}^{\mathrm{IP}}=\left(d_{e i}^{\mathrm{JP}}\right)$ represents the vector of an element contents in domestically consumed goods $i$ and $\mathbf{f}^{\mathrm{JP}}$ is the vector of the domestic final demands. Then, the share of the consumption of alloying elements is formulated as follows:

$$
\begin{aligned}
& \mathbf{S}_{e}^{\mathrm{JP}}=\frac{\sum_{i=1}^{n_{\mathrm{g}}} d_{e i}^{\mathrm{JP}}}{\sum_{i=1}^{n_{\mathrm{g}}} \sum_{j=1}^{n_{\mathrm{c}}} d_{e i j}^{\operatorname{Exp}}+\sum_{i=1}^{n_{\mathrm{g}}} d_{e i}^{\mathrm{P}}} \\
& \mathbf{S}_{e}^{j}=\frac{\sum_{i=1}^{n_{\mathrm{g}}} d_{e i j}^{\mathrm{Exp}}}{\sum_{i=1}^{n_{\mathrm{g}}} \sum_{j=1}^{n_{\mathrm{c}}} d_{e i j}^{\mathrm{Exp}}+\sum_{i=1}^{n_{\mathrm{g}}} d_{e i}^{\mathrm{JP}}}
\end{aligned}
$$

Here, $\mathbf{S}_{\mathbf{e}}^{\mathrm{JP}}$ and $\mathbf{S}_{\mathbf{e}}^{\mathbf{j}}$ represent the share of Japan and country $j$ for the consumption of alloying element $e$ contained in Japanese products and $n_{\mathrm{g}}$ and $n_{\mathrm{c}}$ are the number of goods (528) and countries except Japan (230), respectively.

\subsection{Share of the responsibility}

The embodied GHG emission in the imported alloying element sources for Japan is calculated by multiplying each inventory listed in the next section by imported masses of alloying element sources. The total amounts of embodied GHG emission for each alloying element are the sum of the embodied GHG emissions of corresponding sources imported by Japan. Let $\varepsilon_{e}$ be the scalar of the total amount of GHG emission embodied in an element $e$ introduced to Japan. Applying the share of the consumption of alloying elements obtained by Eqs. (5) and (6) to $\varepsilon_{e}$, the responsibility for GHG emission: $\mathbf{R}_{e}$ is allocated to Japan and other countries importing Japanese products as follows:

$$
\mathbf{R}_{e}=\left(\begin{array}{c}
\mathbf{R}_{e}^{\mathrm{JP}} \\
\mathbf{R}_{e}^{j}
\end{array}\right)=\varepsilon_{e}\left(\begin{array}{c}
\mathbf{S}_{e}^{\mathrm{JP}} \\
\mathbf{S}_{e}^{j}
\end{array}\right)
$$

Here, $\mathbf{R}_{e}^{\mathrm{JP}}$ and $\mathbf{R}_{e}^{j}$ represent the responsibility for GHG emission embodied in an alloying element $e$ attributed to Japan and country $j$, respectively. Consequently, the size of $\mathbf{R}_{\mathbf{e}}$ is $231 \times 1$. Then, by summing up the responsibilities for four alloying elements, total responsibility for country $i: \mathbf{R}=\left(\mathbf{R}_{i}\right)$ is obtained as follows:

$$
\mathbf{R}=\sum_{e \in E} \mathbf{R}_{e}
$$

The set $E$ is for alloying elements including manganese, chromium, nickel, and molybdenum. Because the GHG emissions embodied in each alloying element are varied, the share of responsibility is different from the total share of the consumption of alloying elements. The share of responsibility is then formulated as follows:

$$
\mathbf{Q}=\frac{\mathbf{R}}{\sum_{i=1}^{231} \mathbf{R}_{i}} .
$$




\subsection{Data}

WIO-MFA was conducted based on the Japanese 2005 IO table (Ministry of Industrial Affairs and Communications (Japan) 2009). The sectors of materials and steel mill products in the original IO table were disaggregated in detail and converted into a monetary unit description based on several statistics (Ministry of Economy Trade and Industry (Japan) 2006; The Japan Ferrous Raw Materials Association 2006; JOGMEC 2007). For more detailed information on the definition and disaggregation of the sector, see previous works (Nakajima et al. 2013; Ohno et al. 2014). Commodities considered in this analysis are listed in Additional file 1.

The trade data were organized based on the trade statistics of Japan (Ministry of Finance Japan 2005) by connecting the Harmonized System ("HS") codes (i.e., international standard trade category codes) with the corresponding goods sectors in the IO table. Because the definitions of the sectors in the IO table were sometimes inconsistent with the HS codes, we could not perfectly adjust the amount of trade between the trade statistics and the values of the exports and imports of goods compiled in the IO table. Consequently, the exports from the IO table were allocated based on the ratio of the amount of trade by partner countries calculated from the records in the trade statistics. For partner countries, Nansai et al. (2014) were referred to.

Inventories for the GHG emissions in each raw material production outside Japan were obtained from several sources of inventory data (Ecoinvent 2010; Eckelman 2010; Nuss and Eckelman 2014). Although the inventory of raw material production is varied with production sites, the homogenous inventory was applied in this study because of the lack of information on each site. In this study, we defined four raw materials of alloying elements imported by Japan: ore including concentrate, ferroalloy, pure metal, and others including matt and/or other chemical forms. As Nuss and Eckelman (2014) noted, in some cases the inventory data for each degree of fabrication were unavailable. Therefore, several inventories were estimated by referring to previous studies (Table 1). By applying the obtained inventories, the GHG emissions associated with the raw materials imported by Japan were estimated. The responsibility for GHG emissions was then passed onto Japan as well as other countries and regions according to domestic demand in Japan and the destinations of the exported products. The GHG emissions in the fabrication of products in Japan were not taken into account in order to focus on only the impacts associated with metal production which tend to directly affect the environment in metal mining and producing countries and regions.

Table 1 Inventories for GHG emissions in the production of alloying elements resources

\begin{tabular}{lllcl}
\hline $\mathbf{t} / \mathbf{t}-\mathbf{C O}_{\mathbf{2}} \mathbf{e q}$ & Ore & Ferroalloy & Pure metal & Others \\
\hline $\mathrm{Mn}$ & $0.01^{\mathrm{a}}$ & 1.00 & 2.60 & - \\
$\mathrm{Cr}$ & $0.02^{\mathrm{b}}$ & 1.90 & 26.7 & $4.80^{\mathrm{d}}$ \\
$\mathrm{Ni}$ & $3.82^{\mathrm{c}}$ & 9.20 & 10.9 & $4.36^{\mathrm{c}, \mathrm{e}}$ \\
$\mathrm{Mo}$ & $2.62^{\mathrm{a}}$ & $2.62^{\mathrm{a}}$ & 2.60 & - \\
\hline
\end{tabular}

Mainly referred to Ecoinvent (2010)

a Referred to the inventory for the concentration of each metal

b Referred to the inventory for chromite

c Estimated based on Eckelman (2010)

d Assumed as $\mathrm{Na}_{2} \mathrm{Cr}_{2} \mathrm{O}_{7}$

e Assumed as nickel matt 


\section{Results}

\subsection{Domestic flows of alloying elements}

In 2005, 636, 635, 250 and $29 \mathrm{kt}$ of manganese, chromium, nickel, and molybdenum were imported, respectively, in the form of virgin sources. These were mainly consumed in steelmaking to produce steel mill products from crude steel by employing alloying elements. Accompanying steel mill products, alloying elements are widely distributed through the international supply chain. Indeed, in addition to the imported alloying elements, alloying elements contained in domestically generated steel scrap are utilized in steelmaking. Consequently, the actual flow of alloying elements is greater than that in the imported masses. Given the above, this study discusses the balance of alloying elements in the flow based on the imported masses. The masses of alloying elements remaining in Japan were calculated by subtracting the total exported masses of alloying elements in Japan from the imported masses instead of subtracting the total exported masses from the total consumed masses.

\subsubsection{Manganese}

The top 10 usages of manganese are shown in Fig. 2 for steel mill products (left-hand side) and other products (right-hand side). By separately showing the mass of exports and domestic consumption, we can distinguish the mass of manganese exported from that remaining in Japan. Because manganese is a commonly used element in steelmaking for deoxidation as well as alloying (Nakajima et al. 2008), carbon steel mill products, which require moderate a concentration of manganese (i.e., <1\%), occupy $68 \%$ of the manganese consumption among steel mill products because of their large volume of production. This large consumption of manganese in carbon steel makes it stay in Japan rather than being exported as steel mill and other products. This is because carbon steel mill products are mainly consumed as construction materials domestically: about $230 \mathrm{kt}$ (36\% of manganese derived from imported virgin sources) of manganese was exported to other countries as products. In addition, $18 \mathrm{kt}$ of manganese was exported as raw materials such as ferromanganese.

\subsubsection{Chromium}

The main chromium-consuming steel mill products are stainless steel materials, structural alloy steel, and heat-resistant steel as shown in Fig. 3 (left-hand side). A large part of these are fabricated into various products domestically, about half of which are exported

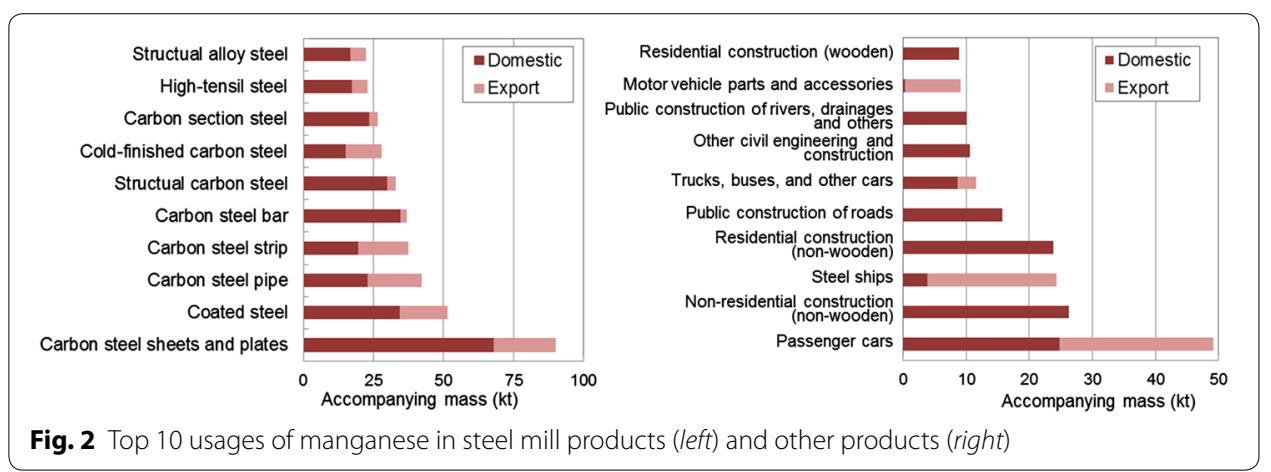




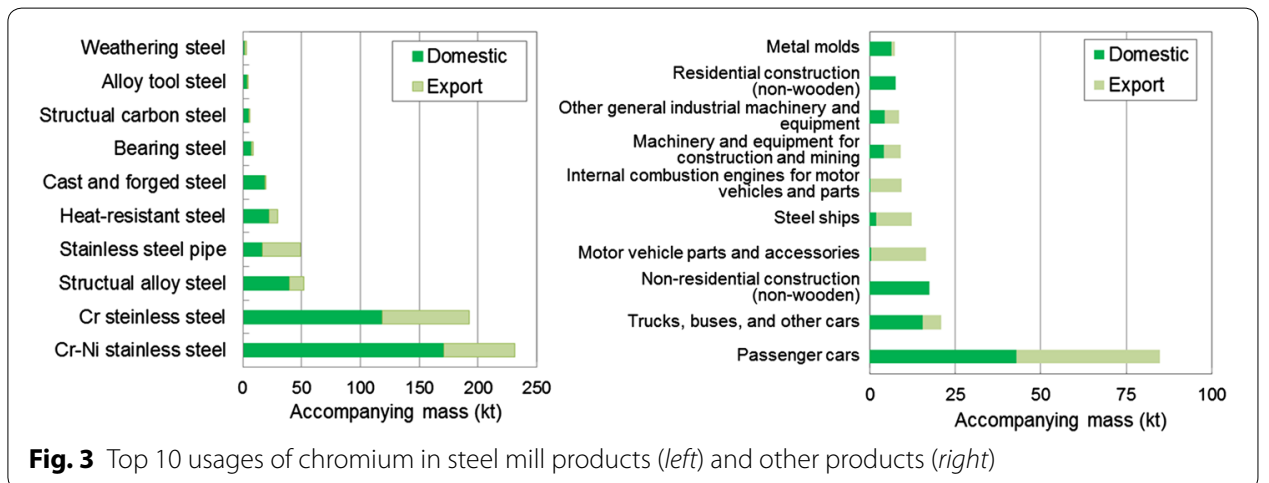

as products. Automobile-related products are the main chromium-containing products. Because 33\% of chromium was accompanying with automobile-related products, their exports highly contributed to chromium exports. In total, $340 \mathrm{kt}$ (54\% $\mathrm{Cr}$ of imported sources) of chromium was exported again as a form of product, while $7 \mathrm{kt}$ of chromium was exported as raw materials.

\subsubsection{Nickel}

$\mathrm{Cr}-\mathrm{Ni}$ stainless steel is the largest nickel-consuming steel mill product as shown in Fig. 4 (left-hand side). Compared with the other elements, the diversity of the nickel usage in steel mill products is lower, being highly concentrated to stainless steel and structural alloy steel. Because of the paired use of nickel with chromium in stainless steel, the main use of nickel was similar to that of chromium (Fig. 4, right-hand side). In this regard, exports of automobile-related products drove exports of nickel as in case of chromium. Overall, about $110 \mathrm{kt}$ (45\% Ni derived from imported virgin sources) of nickel went out from Japan as steel mill and other products. In addition, a relatively large mass of nickel (72 kt) was exported as raw materials such as ferroalloy and matt.

\subsubsection{Molybdenum}

Molybdenum is utilized in various grades of steel mill products as shown in Fig. 5 (lefthand side). Most molybdenum-demanding steel mill products were $\mathrm{Cr}-\mathrm{Ni}$ stainless steel followed by structural steel, heat-resistant steel, and alloy tool steel with relatively small differences in mass among them. On the contrary, in terms of demand, molybdenum

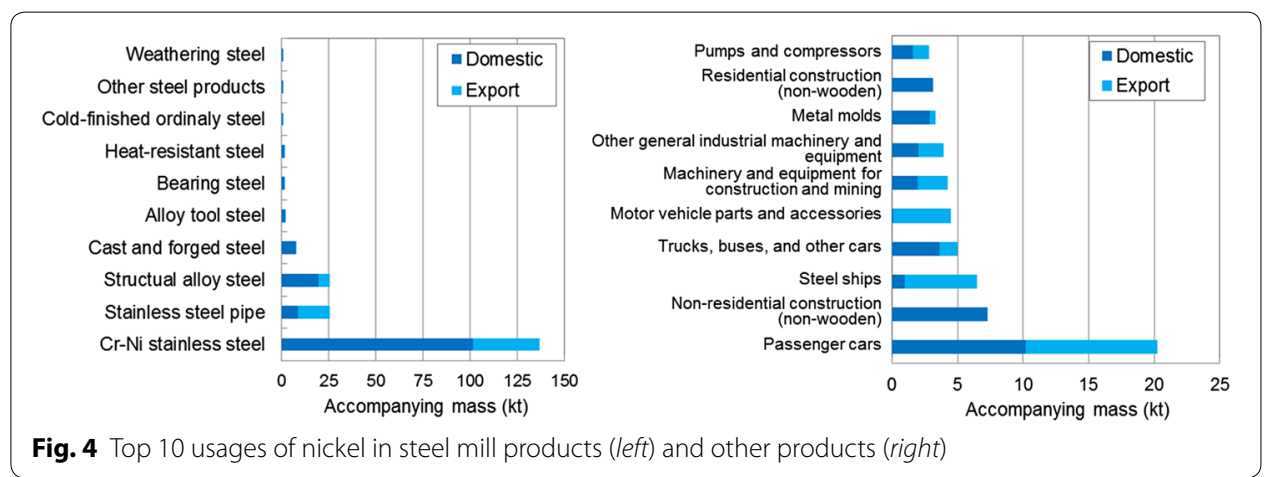




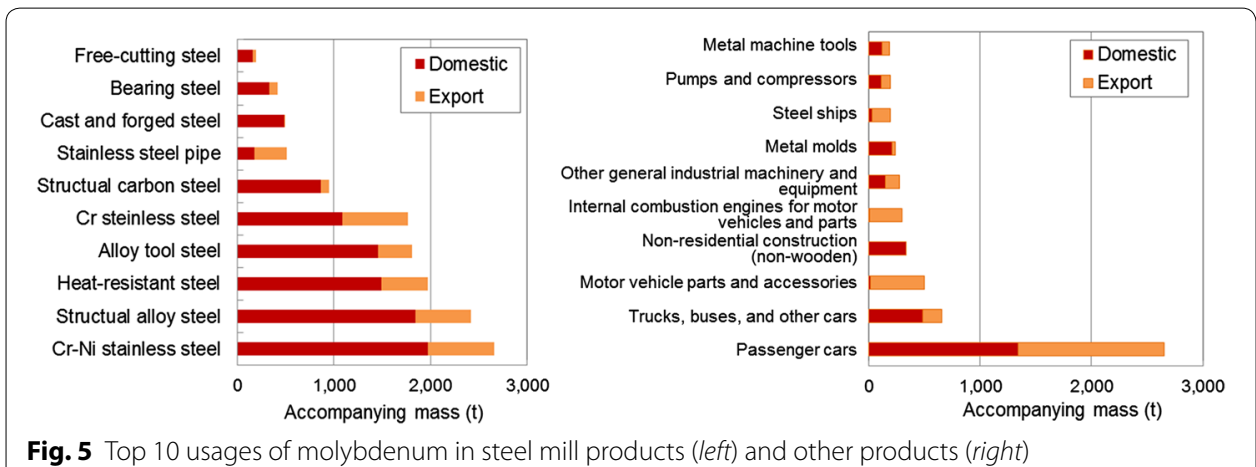

was highly concentrated into automobile-related products (Fig. 5, right-hand side). As a consequence, $7.7 \mathrm{kt}$ (27\% Mo derived from imported virgin sources) of molybdenum was exported with products. Exported molybdenum in raw materials was $0.8 \mathrm{kt}$.

Figure 6 summarizes the flows of the four alloying elements derived from steel. The Sankey diagram was drawn based on IO table. The arrows between element sources and crude steel productions refer to inputs of alloying elements to each category of steelmaking in the IO table. From crude steels to final products, the arrows are drawn based on inputs of crude steels to steel mill products and steel mill products to final products by applying contents of alloying elements in steel materials obtained by WIO-MFA. Finally referring to Eqs. (2) and (3), the arrows were separately drawn toward the export and the domestic consumption. Three kinds of losses (i.e., refinery loss, in-house scrap, and industrial scrap) were calculated based on yield ratio applied to the filtering of the input coefficient matrix mentioned above. Here, the total masses of each alloying element that flowed into steelmaking were standardized as $100 \%$ to present regulated views on the flows with different scales of consumption. Although the alloying elements were mostly provided by virgin sources, steel scrap also contributed to the supply of alloying elements into steelmaking. As mentioned above, the flow of alloying elements is driven by production and the use of alloy steel, including stainless steel. Consequently, more

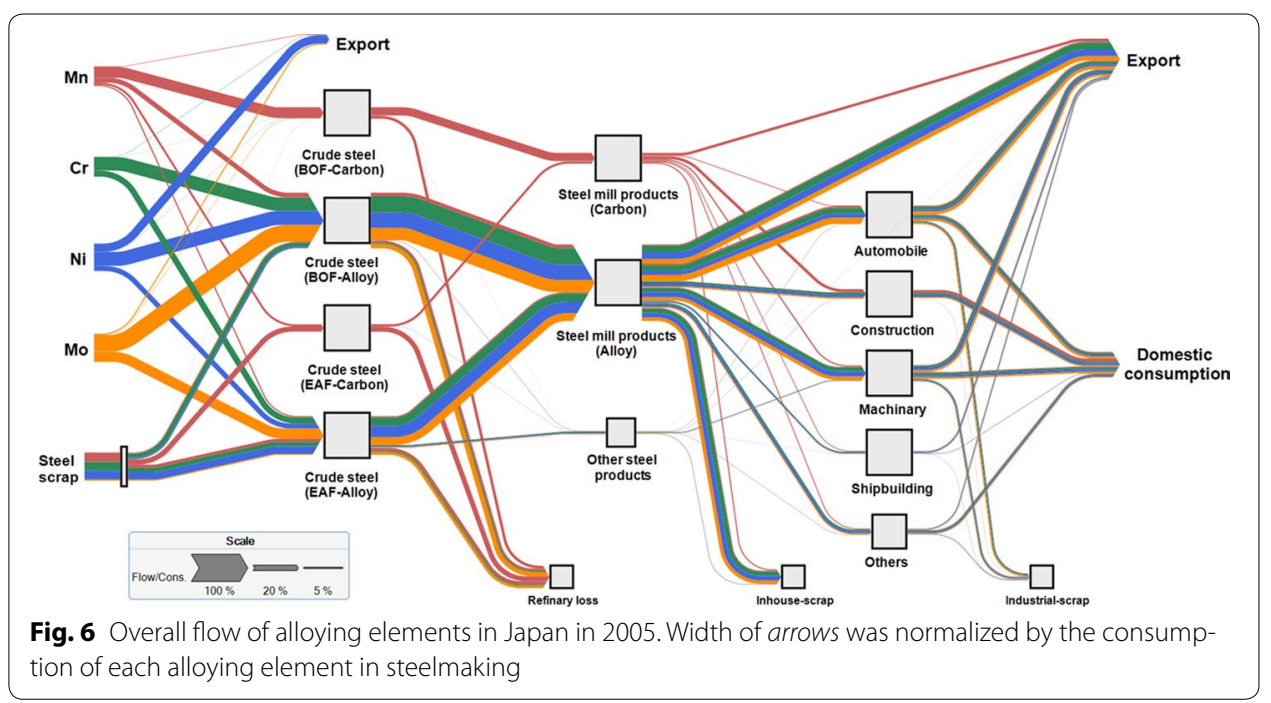


than half of alloying elements are exported with alloy steel mill and other products. This analysis suggests that Japan distributes alloying elements to other countries through its exports of steel mill and final products.

\subsection{International delivery of alloying elements from Japan}

Japanese industries consume large amounts of the world's alloying elements (JOGMEC 2008). Hence, the masses of exported alloying elements still account for a large proportion of global flows. Figure 7 shows the proportion of alloying elements accompanying exports of steel mill products from Japan to various regions globally. As total masses, 130, 190, 61 and $4 \mathrm{kt}$ of manganese, chromium, nickel, and molybdenum were exported as steel mill products, respectively. The mass exports of steel mill products to Asian countries and its accompanying flow of alloying elements were the largest among the considered regions. In particular, China, Korea, Taiwan, and Thailand showed large proportions. Although China is still a rapidly developing country, its advancing steel industry has been producing larger amounts of stainless steel than Japan since 2006 (International Stainless Steel Forum 2013). Therefore, the flow of alloying elements from Japan in recent years would have a rather large discrepancy from the figures provided in this study.

In total, $98 \mathrm{kt}$ (manganese), $25 \mathrm{kt}$ (chromium), $150 \mathrm{kt}$ (nickel), and $4 \mathrm{kt}$ (molybdenum) were exported as products excluding raw materials and steel mill products. In contrast to the case of steel mill products, the flows of alloying elements accompanying the exports of other products were relatively evenly shared by region (Fig. 7). This fact suggests that alloying elements are spread globally in the form of the products made in Japan. At the country level, the USA occupied the largest proportion of accompanying exports, approximately twice as large as those of other countries for all alloying elements. Panama followed the USA for accompanying exports of manganese with products just because of its trade in steel ships. For the other alloying elements, China came in second place followed by other Asian countries. For more results at the country level, see Additional file 2.

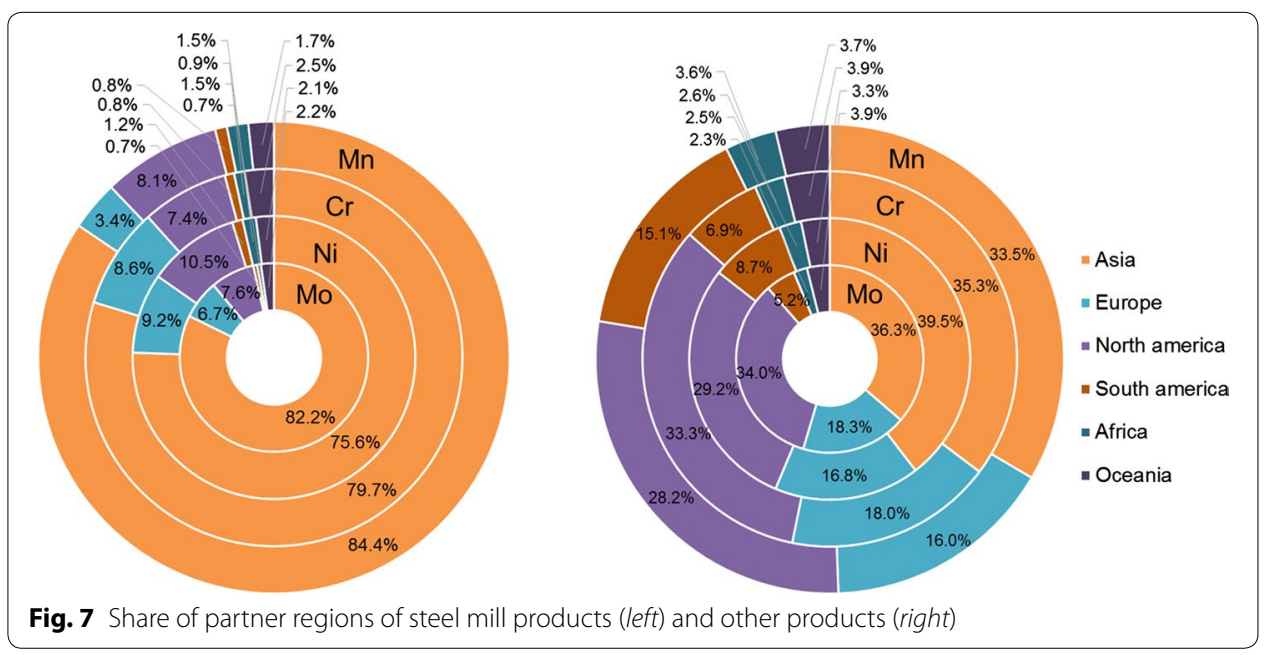




\subsection{Responsibility for environmental impacts}

Japan demands a considerable mass of alloying elements to produce various goods demanded by both in and out of the country, which endows it with a large responsibility for the environmental impacts associated with mining, smelting, and refining in processing countries. In terms of GHG emissions, demands for Japanese products containing alloying elements among all over the world induce 42, 1230, 1420, and $75 \mathrm{kt}$ of GHG embodied in manganese, chromium, nickel, and molybdenum, respectively, in processing countries and region by importing metal sources (Fig. 8). These amounts only include GHG emissions in metal source mining and processing countries before being imported by Japan. Although the target year of accounting is different from this work for 2005, the emissions correspond to about 3, 8, 7, and 4\% of annual GHG emissions for metal production in 2008 according to the work of Nuss and Eckelman (2014). Japanese steel production has been consistent around 110,000-120,000 kt in recent years (112,718 kt in 2005 and 118,739 kt in 2008) (World Steel Association 2015).

Furthermore, because Japan not only imports but also domestically produces some raw materials such as ferroalloys and/or pure metals, the impacts associated with alloying elements passing through Japan would be much higher than the value estimated in this study. According to the IO-based emission inventories developed by Nansai and Moriguchi (2012), Japan emitted 3717 kt- $\mathrm{CO}_{2}$ eq in its ferroalloy production in 2005. Therefore, GHG emissions embodied in alloying elements passing through Japan would be more than double the GHG emissions in origin countries in reality.

The distribution of alloying elements and their embodied GHG emissions associated with Japanese economic activities is summarized in Fig. 9. About half of the alloying elements stayed in Japan. The top 10 distributed countries were mostly located within Asia (Fig. 9 (a-1)). South Korea and Taiwan rose to higher places because they imported a large amount of nickel raw materials from Japan. Thus, their nickel import masses showed a larger proportion than other countries (see Fig. 9 (b-1)). Looking at the breakdown of the distribution by elements (b-1), the larger proportion of manganese stayed in Japan, which represented about half of all remaining alloying elements. It results in the smaller proportion for Japan in terms of the distribution of embodied GHG emissions (39.5\%) compared with that of element masses (49.0\%), as shown in Fig. 9 (a-1), because

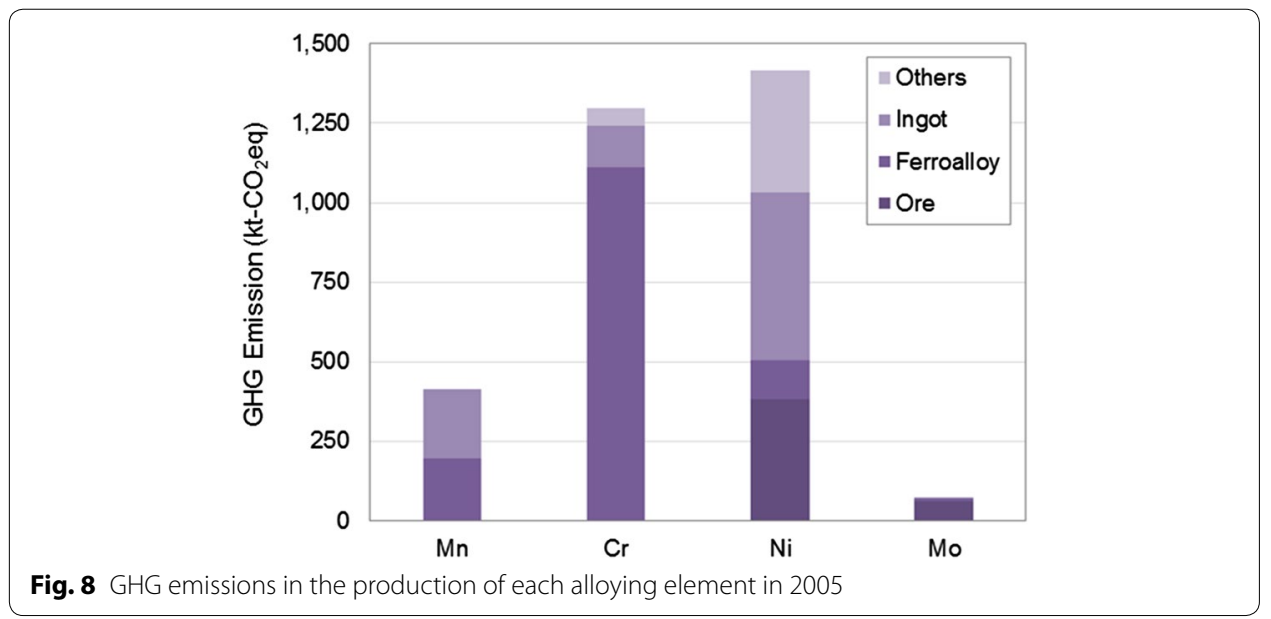




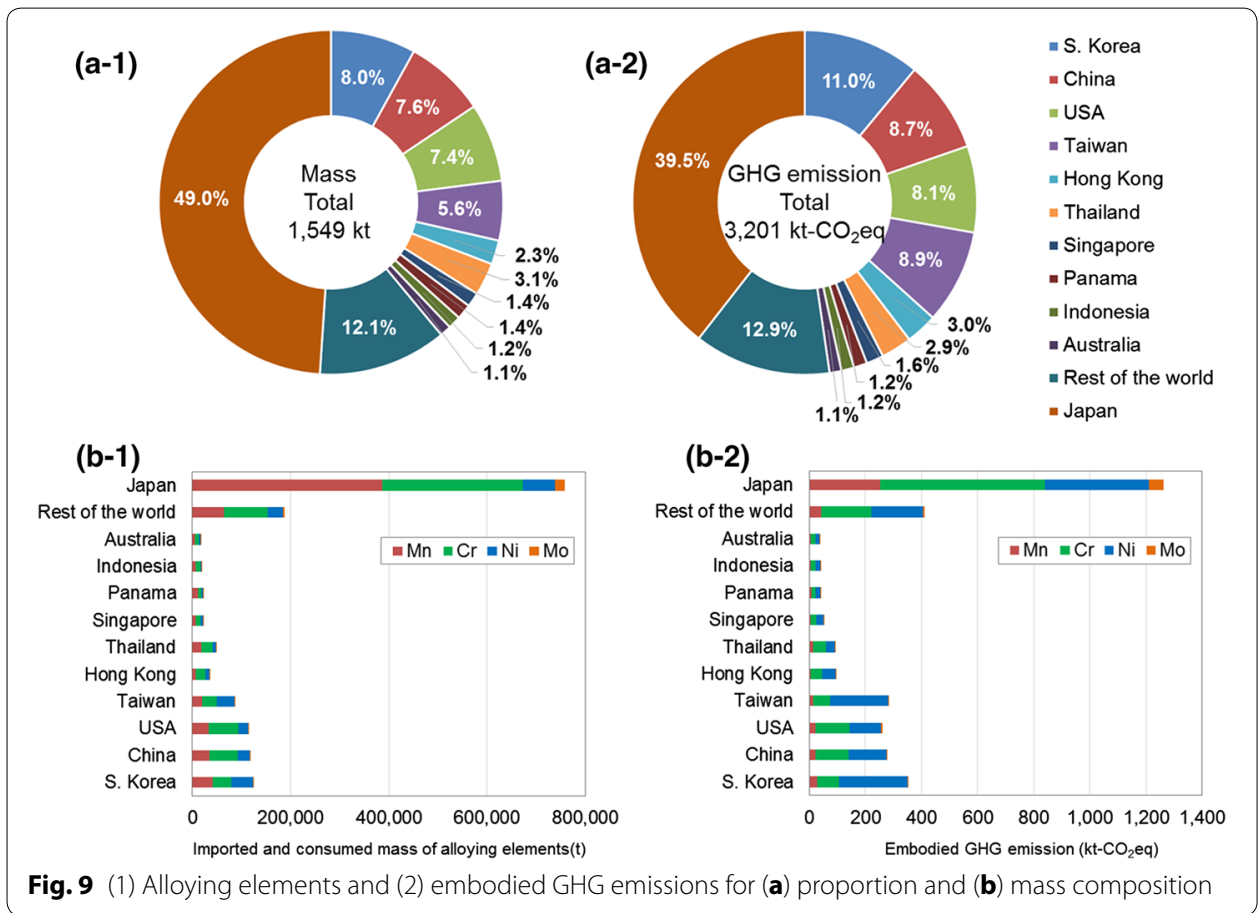

the GHG emissions embodied by manganese sources are relatively small (Table 1). On the contrary, the higher GHG emissions embodied by nickel raised the proportion of the responsibility for GHG emissions in South Korea and Taiwan (Fig. 9 (a-2)). As shown in Fig. 9 (b-2), chromium and nickel dominated the proportion of the embodied GHG emissions. In this regard, the use of $\mathrm{Cr}-\mathrm{Ni}$ stainless steel, containing high amounts of both chromium and nickel, would strongly affect the distribution of the embodied GHG emissions. Therefore, recycling $\mathrm{Cr}-\mathrm{Ni}$ stainless steel should be encouraged, as previous studies of the MFA of chromium and nickel have proposed (Reck et al. 2010; Daigo et al. 2010; Nakajima et al. 2013).

South Korea, China, the USA, and Taiwan are the most important partners in Japanese trade in terms of sharing the responsibility for GHG emissions in alloying element production. Therefore, when Japan tries to reduce the environmental impacts associated with its metal use, it may be able to ask these four countries to contribute to developments of new technology that reduces the environmental impacts in mining, smelting, and refining.

\section{Discussion}

\subsection{Improving resource efficiency}

Alloying elements once collected by Japan are widely distributed across the Japanese economy as well as other countries embodying GHG emissions. Although the proportions of each country's responsibility for GHG emissions are not large individually, demand for Japanese products from other countries has induced large imports of metal sources by Japan. However, reducing demand for Japanese products would be an unsuitable solution to reduce impacts on the metal mining and producing countries 
sustainably. Therefore, Japan must play a key role in the reduction in the impact of metal consumption in this supply chain. If it could maintain supply to other countries and reduce its imports of metal sources, the responsibility shared by each country would decrease. To achieve this, the utilization of urban mines in Japan (i.e., recycling) would be important. Currently, recycling alloying elements from scrap (except process scrap and stainless steel scrap) is rarely taken into account, whereas steel scrap is highly recycled (Ohno et al. 2014). In particular, although automobiles contain a large amount of alloying elements as shown in "Results," most of alloying elements in end-of-life (EoL) vehicles tend to be losses by dissipating into steelmaking slag and/or contaminating into molten steel during the recycling of EoL vehicle-derived steel scrap (Nakajima et al. 2011b, 2013; Ohno et al. 2014). On the contrary, EoL vehicle-derived steel scrap can be a source of alloying elements to substitute $46-63 \mathrm{kt}$ of ferroalloy production by appropriate treatment and sorting during recycling (Ohno et al. 2015). Because this substitutable mass corresponds to a 318-609-kt- $\mathrm{CO}_{2}$ reduction in embodied GHG emissions, it has a significant effect on the reduction in the responsibility. To obtain this benefit from EoL vehicle recycling, appropriate policy and scrap prices must be established (Ohno et al. 2015). For this need, Japan should ask the top four above-mentioned countries (i.e., South Korea, China, the USA, and Taiwan) each sharing around $10 \%$ of the responsibility to contribute.

Similarly, it would also be important to recycle metals in consuming countries themselves. However, the recyclability of alloying elements highly depends on the infrastructure and industries in each country. In the case of alloying elements in EoL vehicle-derived steel scrap, for instance, matured EoL vehicle correction and recycling policies are first required, as the EU (The European Communities 2000) and Japan have already established.

Nansai et al. (2014) characterized the international flow of metals by the technology level of countries. The authors categorized Japan as a "high-level production technology and material-use efficiency" country. If Japanese products containing alloying elements are exported to the countries categorized as the same level as Japan, flows are classified as "green flows," which means that material-use efficiency is the highest because both producing and consuming countries have high levels of technologies. In this case, alloying elements would be well utilized and recycled with high technologies. By contrast, when Japanese products are exported to low-technology-level countries, the flows become "yellow flows," which are defined as "moderately efficient." In these flows, alloying elements in exported products may dissipate because of the lack of recycling technologies in the consumed countries. To reduce the flows in this category, as one potential solution, high-level countries should export their technologies and systems to low-level countries (Nansai et al. 2014). This kind of activity may reduce the need for both primary metal production and embodied environmental impacts not only in the Japan-oriented supply system discussed in this study but also in the global supply chain.

\subsection{Limitations of the model and data}

Because we conduct an MFA based on the IO table for one year, the result only represents a snapshot of the status of that year. Furthermore, this analysis focuses on only Japan-oriented international trade coming into and going out of the country, whereas 
research using multi-regional IO tables covers global trade (Lenzen et al. 2012; Dietzenbacher et al. 2013; Tukker et al. 2013). However, a detailed flow analysis for specific metals, especially non-base metals, requires a high-resolution IO and disaggregation of metal sectors to avoid the flow of metals being aggregated and unable to be distinguished from each other even for Japan who has one of the highest resolution of IO table. In this sense, multi-regional IO tables, which tend to have limited number of sectors for both metals and industrial activities owing to the necessity to homogenize the size of the IO tables for each region, or joint IO tables of a lot of regions with keeping the original sizes of tables, are unsuitable for our purpose. Therefore, to focus on the detailed flow of alloying elements, we selected this approach and demonstrated the trade of specific substances by using the presented snapshot.

In terms of data limitations, we cannot trace the flow of alloying elements associated with second-hand goods because of the lack of trade data for them. Consequently, in addition to the limitation in the adjustment of Japanese IO sectors and HS codes in the trade statistics, this data shortage may cause us to underestimate the real flows. In this regard, we just traced the flow of alloying elements in products produced in 2005, omitting the associated flow of second-hand products.

\section{Conclusion}

In this study, the flows of steel alloying elements in Japan and exports of Japanese products were obtained by means of the WIO-MFA model and by taking data from the trade statistics. Although the content of tiny metals such as alloying elements in highly fabricated products tends to be aggregated and/or ignored, this study covers the detailed content and flow of four alloying elements in order to consider the environmental impacts of the use of each metal separately and thus provide more precise implications. Based on the flow, the responsibility for GHG emissions during metal mining and production was estimated and its distribution among countries and regions in the supply chain calculated. Focusing on four alloying elements in the Japan-oriented supply chain allowed us to describe the role the country plays in the supply chain.

We found that Japan has been a large importer of metal resources as well as a distributer of metals through its product exports. However, this activity has also been driven by consumers of Japanese products. Therefore, the development of eco-friendlier systems and processes with the aim of reducing the environmental impacts associated with metal consumption should be discussed not only in Japan but also in other countries that share the burden of responsibility.

\section{Additional files}

Additional file 1. List of commodities considered in the analysis.

Additional file 2. Top 10 countries in terms of accompanying mass of allying elements with steel mill products and other products except for raw materials. a global scope. YF and TN planned the study and interpreted the implication of the results and the developed method. 


\section{Author details}

${ }^{1}$ Graduate School of Engineering, Tohoku University, Miyagi 980-8579, Japan. ${ }^{2}$ Graduate School of Environmental Studies, Tohoku University, Miyagi 980-8579, Japan. ${ }^{3}$ Center for Material Cycles and Waste Management, National Institute for Environmental Studies, Ibaraki 305-8506, Japan.

\section{Acknowledgements}

This research was supported by a Grant-in-Aid for Scientific Research (A) from the Japan Society for the Promotion of Science (No. 15H01750) and the Japanese Society for the Promotion of Science Grant-in-Aid for JSPS Fellows (No. 258801).

\section{Competing interests}

The authors declare that they have no competing interests.

Received: 16 March 2016 Accepted: 30 November 2016 Published online: 21 December 2016

\section{References}

Daigo I, Matsuno Y, Adachi Y (2010) Substance flow analysis of chromium and nickel in the material flow of stainless steel in Japan. Resour Conserv Recycl 54:851-863. doi:10.1016/j.resconrec.2010.01.004

Dietzenbacher E, Los B, Stehrer R et al (2013) The construction of world input-output tables in the WIOD project. Econ Syst Res 25:71-98. doi:10.1080/09535314.2012.761180

Eckelman MJ (2010) Facility-level energy and greenhouse gas life-cycle assessment of the global nickel industry. Resour Conserv Recycl 54:256-266. doi:10.1016/j.resconrec.2009.08.008

Ecoinvent (2010) Ecoinvent Life Cycle Inventory database v2.2

International Organization of Motor Vehicle Manufactures (OICA) (2015) 2014 Production statistics. http://www.oica.net/ category/production-statistics/2014-statistics/

International Stainless Steel Forum (2013) Stainless steel in figures 2013

Japan Automobile Manufacture Association (JAMA) (2015) Production and Export Summary. http://www.jama-english. jp/statistics/production_export/2014/150130.htm|\#automobile_production_year. Accessed 26 November 2015

Japan Oil Gas and Metals National Corporation (JOGMEC) (2007) Kobutsu Shigen Material Flow 2006 [Material flow of Metal Resource]. JOGMEC, Japan

Japan Oil Gas and Metals National Corporation (JOGMEC) (2008) Metal mining databook 2008 (in Japanese)

Kondo Y, Moriguchi Y, Shimizu H (1998) CO2 Emissions in Japan: influences of imports and exports. Appl Energy 59:163-174. doi:10.1016/S0306-2619(98)00011-7

Lenzen M, Murray J, Sack F, Wiedmann T (2007) Shared producer and consumer responsibility — theory and practice. Ecol Econ 61:27-42. doi:10.1016/j.ecolecon.2006.05.018

Lenzen M, Moran D, Kanemoto Ket al (2012) International trade drives biodiversity threats in developing nations. Nature 486:109-112. doi:10.1038/Nature11145

Ministry of Economy Trade and Industry (Japan) (2006) Yearbook of iron and steel, non-ferrous metals, and fabricated metals statistics. Ministry of Economy, Trade and Industry, Japan

Ministry of Finance Japan (2005) Trade statistics of Japan. Ministry of Finance Japan, Tokyo, Japan

Ministry of Industrial Affairs and Communications (Japan) (2009) 2005 Input-output table for Japan. Ministry of Industrial Affairs and Communications, Tokyo

Nakajima K, Yokoyama K, Nagasaka T (2008) Substance flow analysis of manganese associated with iron and steel flow in japan. ISIJ Int 48:549-553. doi:10.2355/isijinternational.48.549

Nakajima K, Nansai K, Matsubae K et al (2011a) Identifying the substance flow of metals embedded in Japanese International Trade by use of waste input-output material flow analysis (WIO-MFA) model. ISIJ Int 51:1934-1939. doi:10.2355/isijinternational.51.1934

Nakajima K, Takeda O, Miki T et al (2011b) Thermodynamic analysis for the controllability of elements in the recycling process of metals. Environ Sci Technol 45:4929-4936. doi:10.1021/Es104231n

Nakajima K, Ohno H, Kondo Y et al (2013) Simultaneous material flow analysis of nickel, chromium, and molybdenum used in alloy steel by means of input-output analysis. Environ Sci Technol 47:4653-4660. doi:10.1021/es3043559

Nakajima K, Otsuka Y, Iwatsuki Y et al (2014) Global supply chain analysis of nickel: importance and possibility of controlling the resource logistics. Metall Res Technol 111:339-346. doi:10.1051/metal/2014036

Nakamura S, Nakajima K (2005) Waste input-output material flow analysis of metals in the Japanese economy. Mater Trans 46:2550-2553

Nakamura S, Nakajima K, Kondo Y, Nagasaka T (2007) The waste input-output approach to materials flow analysis—concepts and application to base metals. J Ind Ecol 11:50-63

Nansai K, Moriguchi Y (2012) Embodied energy and emission intensity data for Japan using input-output tables (3EID): for 2005 IO table. http://www.cger.nies.go.jp/publications/report/d031/eng/index e.htm

Nansai K, Kagawa S, Kondo Y et al (2009) Improving the completeness of product carbon footprints using a global link input-output model: the case of Japan. Econ Syst Res 21:267-290. doi:10.1080/09535310903541587

Nansai K, Kagawa S, Kondo Y et al (2012) Characterization of economic requirements for a "carbon-debt-free country". Environ Sci Technol 46:155-163. doi:10.1021/Es202007b

Nansai K, Nakajima K, Kagawa S et al (2014) Global flows of critical metals necessary for low-carbon technologies: the case of neodymium, cobalt, and platinum. Environ Sci Technol 48:1391-1400. doi:10.1021/es4033452

Nuss P, Eckelman MJ (2014) Life cycle assessment of metals: a scientific synthesis. PLoS ONE 9:1-12. doi:10.1371/journal. pone.0101298 
Ohno H, Matsubae K, Nakajima K et al (2014) Unintentional flow of alloying elements in steel during recycling of end-oflife vehicles. J Ind Ecol 18:242-253. doi:10.1111/jiec.12095

Ohno H, Matsubae K, Nakajima K et al (2015) Toward the efficient recycling of alloying elements from end of life vehicle steel scrap. Resour Conserv Recycl 100:11-20. doi:10.1016/j.resconrec.2015.04.001

Peters GP (2008) From production-based to consumption-based national emission inventories. Ecol Econ 65:13-23. doi:10.1016/j.ecolecon.2007.10.014

Peters GP, Hertwich EG (2008) $\mathrm{CO}_{2}$ embodied in international trade with implications for global climate policy. Environ Sci Technol 42:1401-1407. doi:10.1021/es072023k

Reck BK, Chambon M, Hashimoto S, Graedel TE (2010) Global stainless steel cycle exemplifies China's rise to metal dominance. Environ Sci Technol 44:3940-3946. doi:10.1021/es903584q

Shigetomi Y, Nansai K, Kagawa S, Tohno S (2015) Trends in Japanese households' critical-metals material footprints. Ecol Econ 119:118-126. doi:10.1016/j.ecolecon.2015.08.010

Shigetomi Y, Nansai K, Kagawa S, Tohno S (2016) Influence of income difference on carbon and material footprints for critical metals: the case of Japanese households. J Econ Struct. doi:10.1186/s40008-015-0033-4

The European Communities (2000) Directive 2000/53/EC of the European Parliament and of the Council on end-of life vehicles

The Japan Ferrous Raw Materials Association (2006) Tetsugen Nenpo 2006 [Annual report of ferrous raw materials for 2005]. The Japan Ferrous Raw Materials Association, Japan

Tukker A, de Koning A, Wood R et al (2013) Exiopol_-development and illustrative analyses of a detailed global MR EE SUT/IOT. Econ Syst Res 25:50-70. doi:10.1080/09535314.2012.761952

United Nations Environment Programme (UNEP) (2011) Decoupling Natural Resource Use and Environmental Impacts from Economic Growth

Wiebe KS, Bruckner M, Giljum S et al (2012) Carbon and materials embodied in the international trade of emerging economies: a multiregional input-output assessment of trends between 1995 and 2005. J Ind Ecol 16:636-646. doi:10.1111/j.1530-9290.2012.00504.x

Wiedmann TO, Schandl H, Lenzen M et al (2015) The material footprint of nations. Proc Natl Acad Sci USA 112:6271-6276. doi:10.1073/pnas.1220362110

World Steel Association (2015) Steel statistical yearbook

\section{Submit your manuscript to a SpringerOpen ${ }^{\circ}$ journal and benefit from:}

- Convenient online submission

Rigorous peer review

- Immediate publication on acceptance

Open access: articles freely available online

- High visibility within the field

- Retaining the copyright to your article

Submit your next manuscript at $\gg$ springeropen.com 